\title{
Características Quantitativas da Carcaça de Novilhos Jovens e Superjovens de Diferentes Grupos Genéticos ${ }^{1}$
}

\author{
Paulo Santana Pacheco ${ }^{2}$, José Henrique Souza da Silva ${ }^{3}$, João Restle ${ }^{4}$, Miguelangelo Ziegler \\ Arboitte $^{5}$, Ivan Luiz Brondani ${ }^{6}$, Dari Celestino Alves Filho ${ }^{7}$, Aline Kellermann de Freitas ${ }^{8}$
}

RESUMO - Objetivou-se, com este estudo, avaliar as características quantitativas da carcaça de novilhos jovens e superjovens dos grupos genéticos 5/8Charolês (CH) 3/8Nelore (NE) e 5/8NE 3/8CH e a relação entre as variáveis estudadas. Os animais foram terminados em confinamento até atingirem peso de $430 \mathrm{~kg}$. Novilhos jovens foram abatidos com média de 22,8 meses e os superjovens com 15,2 meses de idade. A dieta alimentar continha relação volumoso:concentrado de 60:40 (com base na matéria seca), contendo 10,25\% de proteína bruta e 3,18 Mcal de energia digestível/kg de matéria seca. O delineamento experimental foi o inteiramente casualizado, com seis repetições, em arranjo fatorial 2 x 2 (duas categorias x dois grupos genéticos). Houve interação para rendimentos de carcaça quente (RCQ) e fria (RCF). Novilhos 5/8NE 3/8CH superjovens apresentaram maior RCQ (57,51 vs 54,10\%) e RCF (54,84 vs 52,62\%) que os 5/8CH 3/8NE de mesma categoria e os 5/8NE 3/8CH da categoria jovem (55,43 e 53,84\%, respectivamente). Novilhos superjovens apresentaram carcaças com maior espessura de gordura subcutânea, em mm $(6,29$ vs 3,22) e em mm/100 kg peso de carcaça fria (2,71 vs 1,39), espessura de coxão (26,58 vs25,17 cm), porcentagem de costilhar (13,45 vs 11,34) e menor porcentagem de traseiro (50,33 vs 51,39) que os jovens. Entre os grupos genéticos, animais 5/8CH 3/8NE apresentaram carcaças com melhor conformação (11,00 vs 10,33 pontos), e os 5/8NE 3/8CH maior comprimento de perna (72,46 vs 69,92 cm), comprimento de braço (41,92 vs 38,46 cm) e percentagem de dianteiro (37,54 vs 36,43). A conformação da carcaça correlacionou-se positivamente com área do músculo Longissimus dorsi $(\mathrm{r}=0,35)$, espessura de coxão $(\mathrm{r}=0,23)$ e perímetro de braço $(r=0,15)$, e negativamente com a quebra ao resfriamento da carcaça $(r=-0,35)$. Entre espessura de gordura subcutânea e percentagem de costilhar, o coeficiente de correlação foi 0,55.

Palavras-chave: Bos indicus, Bos taurus, cruzamento, espessura de gordura subcutânea, ganho compensatório, rendimento de carcaça

\section{Carcass Quantitative Characteristics of Steers and Young Steers of Different Genetic Groups}

ABSTRACT - The objective of this trial was to evaluate the carcass quantitative characteristics of two categories: steers and young steers, from two genetic groups, 5/8Charolais $(\mathrm{CH}) 3 / 8 \mathrm{Nelore}(\mathrm{NE})$ and 5/8NE 3/8CH, and to evaluate the relation among studied variables. The animals were fedlot finished until reaching $430 \mathrm{~kg}$ of body weight. Steers were slaughtered averaging $22.8 \mathrm{months}$ old and young steers 15.2 months old. The diet, roughage:concentrate ratio of 60:40 (dry matter basis), contained 10.25\% crude protein and 3.18 Mcal of digestible energy/kg of dry matter. The experiment was analyzed as a complete randomized design with six replicates, according to a 2 x 2 (two categories x two genetic groups) factorial scheme. Significant interactions were verified for hot (HDP) and cold (CDP) dressing percentage. 5/8NE 3/8CH young steers showed higher HDP (57.51 vs. 54.10\%) and CDP (54.84 vs. 52.62\%) than 5/8CH 3/8NE of same category and in relation to 5/8NE 3/8CH steers (55.43 vs. 53.84\%, respectively). Young steers showed carcasses with higher subcutaneous fat thickness in $\mathrm{mm}(6.29 \mathrm{vs}$. 3.22) and mm/100 kg cold carcass weight (2.71 vs. 1.39), cushion thickness (26.58 vs. $25.17 \mathrm{~cm})$, sidecut percentage (13.45 vs. 11.34) and lower sawcut percentage (50.33 vs. 51.39) than steers. Between genetic groups, 5/8CH 3/8NE animals showed carcasses with higher conformation score (11.00 vs. 10.33 points), and 5/8NE 3/8CH higher leg length (72.46 vs. $69.92 \mathrm{~cm}$ ), arm length (41.92 vs. $38.46 \mathrm{~cm}$ ) and forequarter percentage (37.54 vs. 36.43). Carcass conformation was positively correlated with $L$ ongissimus dorsi area $(r=0.35)$, cushion thickness $(r=0.23)$ and arm perimeter $(r=0.15)$, and negatively with chilling loss of carcass $(r=-0.35)$. The correlation coefficient was of 0.55 between subcutaneous fat thickness and sidecut percentage.

Key Words: Bos indicus, Bos Taurus, compensatory gain, crossbreeding, dressing percentage, subcutaneous fat thickness

\footnotetext{
1 Parte da Dissertação de Mestrado do primeiro autor - PPGZ/UFSM.

2 Zootecnista, MSc. Doutorando do PPGCA-UFG. E.mail: pspacheco@pop.com.br

3 Engenheiro Agrônomo, PhD. Professor Adjunto do Departamento de Zootecnia da UFSM.

4 Engenheiro Agrônomo, PhD. Pesquisador Visitante/CNPq-DPA/UFG. E-mail: jorestle@terra.com.br

5 Zootecnista, MSc. Professor do Departamento de Zootecnia da UFSM.

6 Zootecnista, Dr. Professor Adjunto do Departamento de Zootecnia da UFSM.

7 Engenheiro Agrônomo, MSc. Professor Assistente do Departamento de Zootecnia da UFSM.

8 Zootecnista. Aluna de Mestrado do PPGCA-UFG. Bolsista CNPq.
} 


\section{Introdução}

Com o aumento na quantidade de carne bovina exportada desde o final da década de 90, a cadeia produtiva deste segmento no Brasil cada vez mais alcança destaque no cenário mundial. Segundo ANUALPEC (2003), este quadro é resultante do aumento da demanda do mercado internacional, liderada por países asiáticos e pelos Estados Unidos, dos baixos custos de produção da carne bovina brasileira, tornando-a altamente competitiva e do fato de países tradicionalmente concorrentes, como Argentina, Estados Unidos e Austrália, estarem próximos do limite de sua capacidade produtiva.

Contudo, o país precisa estar atento para atender às exigências do mercado consumidor, principalmente quanto à qualidade do produto final, ou seja, carcaça e carne. Para conquistar novos mercados e manter os já conquistados, a cadeia produtiva da carne bovina brasileira deve se organizar e modernizar-se, visando a produção com eficiência, tanto técnica como econômica, e qualidade.

Restle \& Vaz (2003) demonstraram que a eficiência na pecuária de corte está relacionada à redução na idade de abate, ao potencial genético do animal e à alimentação de qualidade. Além disso, alertaram para a importância do papel da pesquisa nacional no processo de monitoramento da qualidade da carne produzida.

Entre as características da carcaça, o rendimento de carcaça e dos cortes comerciais, o peso e o grau de acabamento são as principais variáveis de interesse comercial para os frigoríficos (Restle et al., 1999b; Costa et al., 2002; Arboitte et al., 2004). O peso de carcaça normalmente exigido pelos frigoríficos é acima de $230 \mathrm{~kg}$. No entanto, carcaças com menor peso (entre 180 e 230 kg) são cada vez mais aceitas pelos açougues e supermercados, que associam pesos mais leves com animais mais jovens e, portanto, carne de melhor qualidade (Restle et al., 1999 b).

Quanto ao grau de acabamento, os frigoríficos exigem carcaças com espessura de gordura subcutânea mínima de $3 \mathrm{~mm}$ e máxima de $6 \mathrm{~mm}$. Abaixo de $3 \mathrm{~mm}$, ocorre escurecimento da parte externa dos músculos expostos ao resfriamento, conferindo aspecto visual indesejável prejudicando a comercialização, e aumento da quebra ao resfriamento, decorrente da maior perda de líquidos, entre outros fatores (Müller, 1987; Restle et al., 1997; Restle et al., 1999 b; Costa et al., 2002). Acima de 6 mm, o prejuízo para o produtor se dá pelo recorte do excesso de gordura (processo também denominado toalete) antes da pesagem da carcaça e, para o frigorífico se dá pelo maior custo operacional envolvido neste processo (Costa et al., 2002).

Em extensa revisão de Restle \& Vaz (2003), envolvendo 17 estudos com novilhos superjovens de 10 diferentes grupos genéticos e 24 estudos com novilhos jovens de 14 diferentes grupos genéticos, os autores verificaram que, em média, espera-se diferença de 21,3\% na espessura de gordura subcutânea e apenas $2,4 \%$ no rendimento de carcaça em favor dos animais superjovens.

Neste experimento, objetivou-se avaliar as características quantitativas da carcaça de novilhos pertencentes às categorias jovem ou superjovem, dos grupos genéticos 5/8Charolês $3 / 8$ Nelore ou $5 / 8$ Nelore $3 / 8$ Charolês e a relação entre as variáveis estudadas.

\section{Material e Métodos}

O experimento foi conduzido no Setor de Bovinocultura de Corte do Departamento de Zootecnia da Universidade Federal de Santa Maria, no município de Santa Maria - RS, localizado na região fisiográfica Depressão Central, a 153 m de altitude, onde, segundo classificação de Köppen, o clima é do tipo subtropical úmido (cfa) (Moreno, 1961).

Foram avaliadas as características quantitativas da carcaça de 24 novilhos castrados com, em média, sete meses de idade, provenientes do mesmo rebanho, dos grupos genéticos 5/8Charolês ( $\mathrm{CH}$ ) 3/8Nelore (NE) ou $5 / 8 \mathrm{NE} 3 / 8 \mathrm{CH}$, pertencentes às categorias: jovem (caracterizada por animais abatidos com idade de 20 a 24 meses), abatidos com média de 22,8 meses de idade; ou superjovem (caracterizada por animais abatidos com idade de 12 a 16 meses), abatidos com média de 15,2 meses de idade.

Durante o período de terminação em confinamento, os animais foram alimentados à vontade duas vezes ao dia, de manhã (8 h) e à tarde (17 h).

A dieta foi calculada segundo o NRC (1996), objetivando ganho de peso médio diário de 1,6 kg/ animal, estimando-se consumo de $2,5 \mathrm{~kg}$ de matéria seca (MS)/100 kg peso vivo (PV). Para todos os animais, foi utilizada relação volumoso:concentrado de 60:40 (base na MS), com dieta contendo 10,25\% de proteína bruta e 3,18 Mcal de energia digestível/ 
kg de MS. A composição percentual da dieta está apresentada na Tabela 1.

Ao atingirem peso de abate próximo ao pretendido (430 kg), os animais foram submetidos a jejum de sólidos de 14 horas, para a pesagem final de abate. Em seguida, foram transportados a um frigorífico comercial a $25 \mathrm{~km}$ do local do experimento e abatidos segundo o fluxo normal da empresa. O período médio de alimentação em confinamento foi de 35 dias para os novilhos jovens e 143 dias para os superjovens.

Após o abate, as duas meia-carcaças foram identificadas, pesadas e encaminhadas à câmara de resfriamento, para se obter o peso de carcaça quente. Após resfriamento por 24 horas sob temperatura oscilando entre zero e $1^{\circ} \mathrm{C}$, as carcaças foram novamente pesadas, para obtenção do peso de carcaça fria. A partir destas duas pesagens, foram determinados os rendimentos de carcaça quente e fria, respectivamente, com base no peso de abate tomado no local do experimento.

Ainda nas duas meia-carcaças, foram determinadas, subjetivamente, as pontuações referentes à conformação e maturidade fisiológica, segundo metodologia descrita por Müller (1987).

A meia-carcaça fria esquerda foi separada nos cortes comerciais: traseiro (ou serrote), que corresponde à região posterior da carcaça, separada do dianteiro, entre a quinta e sexta costelas, e do costilhar (ou ponta-de-agulha), a aproximadamente $20 \mathrm{~cm}$ da coluna vertebral; dianteiro, que compreende pescoço, paleta, braço e cinco costelas; e costilhar ou

Tabela 1 - Composição da dieta oferecida aos animais Table 1 - Composition of the diet offered to the animals

\begin{tabular}{lc}
\hline $\begin{array}{l}\text { Ingrediente } \\
\text { Ingredient }\end{array}$ & $\% *$ \\
\hline $\begin{array}{l}\text { Silagem de milho } \\
\text { Corn silage }\end{array}$ & 60,00 \\
$\begin{array}{l}\text { Farelo de trigo } \\
\text { Wheat bran }\end{array}$ & 28,24 \\
$\begin{array}{l}\text { Sorgo grão } \\
\text { Sorghum grain }\end{array}$ & 10,07 \\
$\begin{array}{l}\text { Uréia(45-00-00) } \\
\text { Urea (45-00-00) } \\
\text { Calcário calcítico }\end{array}$ & 0,17 \\
$\begin{array}{l}\text { Limestone } \\
\text { Sal comum (NaCl) }\end{array}$ & 1,02 \\
$\begin{array}{l}\text { Salt } \\
\left.\text { Ionóforo (Rumensin }{ }^{\circledR}\right)\end{array}$ & 0,48 \\
Ionophore & 0,0128 \\
\hline
\end{tabular}

* Expresso na matéria seca (Express in dry matter). ponta-de-agulha, região da sexta costela mais os músculos abdominais. Os cortes foram pesados individualmente, determinando-se suas proporções em relação à meia-carcaça.

Na meia-carcaça fria direita, foram avaliadas as seguintes características métricas: comprimento de carcaça, tomada do bordo cranial medial da primeira costela e o bordo anterior do osso púbis; comprimento de perna, correspondente à distância entre o bordo anterior do osso púbis e a articulação tíbio-tarsiana; espessura de coxão, medido entre a face lateral e a face medial da porção superior do coxão, com auxílio de um compasso; comprimento de braço, distância da articulação rádio carpiana até a extremidade do olécrano; e perímetro do braço, perímetro da região medial do mesmo.

Ainda na meia-carcaça direita, foi realizada uma secção na altura da $12^{\mathrm{a}}$ costela, para exposição do músculo Longissimus dorsi, traçando-se o seu contorno em papel vegetal, para posterior determinação de sua área $\left(\mathrm{cm}^{2}\right)$ em mesa digitalizadora através do software Siter 1.0, também denominada área de olho de lombo. Nesta mesma secção, foi determinada a espessura de gordura subcutânea, pela média aritmética de três observações em torno do músculo Longissimus dorsi exposto (Müller, 1987).

O delineamento experimental adotado foi o inteiramente casualizado, em arranjo fatorial $2 \times 2$ (duas categorias $\mathrm{x}$ dois grupos genéticos). Cada tratamento foi composto por seis repetições, em que cada animal constituiu uma unidade experimental. Foram realizadas as análises de variância e de correlação de Pearson, aplicando-se os testes $\mathrm{F}$ e o teste Tukey, este último quando a interação foi significativa a 5\%, utilizando-se o programa estatístico SAS (1997). O modelo matemático empregado na análise de variância foi:

$$
\Upsilon_{i j k}=m+G G_{i}+C_{j}+\left(G G^{*} C\right)_{i j}+\varepsilon_{i j k},
$$

em que: $\Upsilon_{i j k}=$ variáveis dependentes; $\mathrm{m}=$ média geral de todas as observações; $\mathrm{GG}_{i}=$ efeito do grupo genético de ordem “ $i$ ”, sendo $1=5 / 8$ Charolês $3 /$ 8Nelore e 2 = 5/8Nelore 3/8Charolês; $C_{j}=$ efeito da categoria de ordem “ $j$ ”, sendo $1=$ jovem e $2=$ superjovem; $\left(\mathrm{GG}^{*} \mathrm{C}\right)_{i j}=$ interação do i-ésimo grupo genético e da j-ésima categoria; $\varepsilon_{i j k}=$ erro aleatório residual, NID $\left(0, \sigma^{2}\right)$.

Os dados foram testados quanto à normalidade, pelo teste de Shapiro-Wilk (SAS, 1997), efetuando-se, quando necessário, a transformação da raiz quadrada dos dados dos parâmetros. 


\section{Resultados e Discussão}

Na Tabela 2 encontram-se os valores médios referentes aos pesos de abate, de carcaça quente e fria, rendimentos de carcaça quente e fria e quebra ao resfriamento da carcaça, de acordo com a categoria e o grupo genético dos novilhos.

Verificou-se que o peso de abate não diferiu $(P>0,05)$ entre os níveis dos diferentes fatores estudados, apresentando valores médios próximos ao pre- conizado neste estudo (430 kg). Assim como o peso de abate, os pesos médios de carcaça quente e fria foram similares entre os diferentes grupos genéticos e entre as categorias avaliadas. Entre as categorias, o peso de carcaça quente oscilou entre 239,25 e $242,52 \mathrm{~kg}$ e o de carcaça fria, entre 232,38 e 233,52 kg.

Houve interação significativa de categoria e grupo genético para rendimentos de carcaça quente e fria e quebra ao resfriamento da carcaça. Novilhos 5/8NE 3/8CH superjovens apresentaram maiores rendimen-

Tabela 2 - Médias e erros-padrão para peso de abate, pesos de carcaça quente e fria, rendimentos de carcaça quente e fria, e quebra ao resfriamento da carcaça, de acordo com a categoria e o grupo genético

Table 2 - Means and standard errors for slaughter weight, hot and cold carcass weights, hot and cold dressing percentages, and chilling loss of carcass, according to category and genetic group

\begin{tabular}{|c|c|c|c|}
\hline \multirow[t]{2}{*}{$\begin{array}{l}\text { Grupo genético } \\
\text { Genetic group }\end{array}$} & \multicolumn{2}{|c|}{$\begin{array}{l}\text { Categoria } \\
\text { Category }\end{array}$} & \multirow[t]{2}{*}{$\begin{array}{l}\text { Média } \\
\text { Mean }\end{array}$} \\
\hline & $\begin{array}{l}\text { Jovem } \\
\text { Steer }\end{array}$ & $\begin{array}{l}\text { Superjovem } \\
\text { Young steer }\end{array}$ & \\
\hline & \multicolumn{2}{|c|}{$\begin{array}{l}\text { Peso de abate, } \mathrm{kg} \\
\text { Slaughter weight, } \mathrm{kg}\end{array}$} & \\
\hline $\begin{array}{l}\text { 5/8CH3/8NE } \\
\text { 5/8NE3/8CH } \\
\text { Média (Mean) }\end{array}$ & $\begin{array}{l}437,17 \pm 16,05 \\
425,50 \pm 16,05 \\
431,33 \pm 11,35 \\
\end{array}$ & $\begin{array}{l}434,00 \pm 16,05 \\
435,50 \pm 16,05 \\
434,75 \pm 11,35 \\
\end{array}$ & $\begin{array}{l}435,58 \pm 11,35 \\
430,50 \pm 11,35\end{array}$ \\
\hline & \multicolumn{2}{|c|}{$\begin{array}{c}\text { Peso de carcaça quente, kg } \\
\text { Hot carcass weight, } \mathrm{kg}\end{array}$} & \\
\hline $\begin{array}{l}\text { 5/8CH3/8NE } \\
\text { 5/8NE 3/8CH } \\
\text { Média (Mean) }\end{array}$ & $\begin{array}{l}246,00 \pm 9,10 \\
232,50 \pm 9,10 \\
239,25 \pm 6,44\end{array}$ & $\begin{array}{l}234,75 \pm 9,10 \\
250,28 \pm 9,10 \\
242,52 \pm 6,44\end{array}$ & $\begin{array}{l}240,38 \pm 6,44 \\
241,39 \pm 6,44\end{array}$ \\
\hline Média (Mean) & \multicolumn{2}{|c|}{$\begin{array}{l}\text { Peso de carcaça fria, } \mathrm{kg} \\
\text { Cold carcass weight, } \mathrm{kg}\end{array}$} & \\
\hline $\begin{array}{l}\text { 5/8CH3/8NE } \\
\text { 5/8NE 3/8CH } \\
\text { Média (Mean) }\end{array}$ & $\begin{array}{l}238,33 \pm 8,85 \\
226,43 \pm 8,85 \\
232,38 \pm 6,26 \\
\end{array}$ & $\begin{array}{l}228,35 \pm 8,85 \\
238,68 \pm 8,85 \\
233,52 \pm 6,26 \\
\end{array}$ & $\begin{array}{l}233,34 \pm 6,26 \\
232,56 \pm 6,26\end{array}$ \\
\hline Média (Mean) & \multicolumn{2}{|c|}{$\begin{array}{l}\text { Rendimento de carcaça quente, \% } \\
\text { Hot dressing percentage, \% }\end{array}$} & \\
\hline $\begin{array}{l}\text { 5/8CH3/8NE } \\
\text { 5/8NE3/8CH } \\
\text { Média (Mean) }\end{array}$ & $\begin{array}{c}56,30 \mathrm{ab} \pm 0,60 \\
54,56 \mathrm{bc} \pm 0,60 \\
55,43 \pm 0,42 \\
\end{array}$ & $\begin{array}{c}54,10 \mathrm{c} \pm 0,60 \\
57,51 \mathrm{a} \pm 0,60 \\
55,81 \pm 0,42 \\
\end{array}$ & $\begin{array}{l}55,20 \pm 0,42 \\
56,03 \pm 0,42\end{array}$ \\
\hline Média (Mean) & $\begin{array}{r}\text { Rendir } \\
\text { Cold }\end{array}$ & $\begin{array}{l}\text { a fria, } \% \\
\text { tage, } \%\end{array}$ & \\
\hline $\begin{array}{l}\text { 5/8CH3/8NE } \\
\text { 5/8NE3/8CH } \\
\text { Média (Mean) }\end{array}$ & $\begin{array}{c}54,54 \mathrm{ab} \pm 0,56 \\
53,14 \mathrm{bc} \pm 0,56 \\
53,84 \pm 0,39\end{array}$ & $\begin{array}{c}52,62 \mathrm{c} \pm 0,56 \\
54,84 \mathrm{a} \pm 0,56 \\
53,73 \pm 0,39\end{array}$ & \multirow[t]{2}{*}{$\begin{array}{l}53,58 \pm 0,39 \\
53,99 \pm 0,39\end{array}$} \\
\hline Média (Mean) & \multicolumn{2}{|c|}{$\begin{array}{l}\text { Quebra no resfriamento, \% } \\
\text { Chilling loss, \% }\end{array}$} & \\
\hline $\begin{array}{l}\text { 5/8CH3/8NE } \\
\text { 5/8NE3/8CH } \\
\text { Média (Mean) }\end{array}$ & $\begin{array}{c}3,13 b \pm 0,26 \\
2,59 b \pm 0,26 \\
2,86 \pm 0,18\end{array}$ & $\begin{array}{c}2,74 \mathrm{~b} \pm 0,26 \\
4,63 \mathrm{a} \pm 0,26 \\
3,68 \pm 0,18\end{array}$ & $\begin{array}{l}2,93 \pm 0,18 \\
3,61 \pm 0,18\end{array}$ \\
\hline
\end{tabular}

a, b, c Médias seguidas por letras minúsculas diferentes, para a mesma característica, diferem $(P<0,05)$ pelo teste Tukey. a, b, c Means followed by different small letters, for the same characteristic, differ $(P<.05)$ by Tukey test. 
tos de carcaça quente (57,51 vs 54,10\%) e fria (54,84 vs $52,62 \%$ ) que os $5 / 8 \mathrm{CH} 3 / 8 \mathrm{NE}$ de mesma categoria e que os $5 / 8 \mathrm{NE} 3 / 8 \mathrm{CH}$ da categoria jovem $(55,43$ e $53,84 \%$, respectivamente).

Como observado por Restle \& Vaz (2003), que compararam as características de carcaça a partir da compilação de diversos estudos com novilhos jovens e superjovens, verificou-se semelhança para rendimento de carcaça entre estas categorias $(53,97$ vs $54,27 \%$, respectivamente).

Vários estudos demonstraram maior rendimento de carcaça em genótipos zebuínos em relação aos taurinos (Perobelli et al., 1995; Feijó et al., 1997; Restle et al., 1999a), e inclusive em genótipos com maior participação de zebuínos (Galvão et al., 1991; Restle et al., 1999a; Restle et al., 2000; Vaz et al., 2002a, b), demonstrando o marcante efeito aditivo destes genótipos para esta característica.

Segundo Restle et al. (1999b) e Costa et al. (2002), o peso de carcaça e o rendimento de carcaça são medidas de interesse dos frigoríficos, para avaliação do valor do produto adquirido e dos custos operacionais, visto que carcaças com pesos diferentes demandam mesma mão-de-obra e mesmo tempo de processamento. Atualmente, o peso de carcaça é a forma de comercialização mais utilizada pelos frigoríficos.

Na média entre categorias e grupos genéticos (Tabela 2), os animais superjovens atingiram os pesos mínimos de carcaça quente e fria normalmente exigidos pelos frigoríficos (230 kg ou 15@), evitando-se penalização no valor pago ao produtor. No entanto, Restle et al. (1999 b) comentam que carcaças de novilhos superjovens com peso superior a $180 \mathrm{~kg}$ estão sendo gradativamente aceitas pelos açougues e supermercados, que geralmente associam pesos mais leves de carcaça com carne de melhor qualidade.

Quanto à quebra durante o processo de resfriamento da carcaça, houve interação significativa de categoria e grupo genético. Novilhos 5/8NE 3/ 8CH superjovem apresentaram maior quebra (4,63\%) que os 5/8CH 3/8NE (2,74\%) de mesma categoria e que os jovens (média de 2,86\%). Estudos apontam para associação negativa entre quebra ao resfriamento da carcaça e espessura de gordura subcutânea (Müller, 1987; Galvão et al., 1991; Perobelli et al., 1995; Restle et al., 2000; Arboitte et al., 2004). Segundo Müller (1987), menores índices de quebras são verificados em carcaças com maior grau de acabamento, uma vez que a espessura de gordura funciona como isolante, evitando as perdas por desidratação. Neste estudo, isto não se confirmou, pois os novilhos da categoria superjovem apresentaram carcaças com maior espessura de gordura subcutânea (Tabela 4). Lawrie (1970) e Restle etal. (1997) explicam que, possivelmente, a variação na quebra ao resfriamento pode estar associada a oscilações que ocorrem na câmara fria, como temperatura, velocidade do vento, número de carcaças, e que podem variar em função da data de abate dos animais, como ocorreu neste experimento.

No entanto, a quebra ao resfriamento apresentou correlação significativa com a conformação da carcaça $(r=-0,35)$, ou seja, menores perdas de líquidos durante o processo de resfriamento na câmara fria foram atribuídas a carcaças com maior musculosidade (Tabela 6), o que coincide com as diferenças numéricas verificadas na Tabela 3 para conformação da carcaça. No estudo de Flores (1997), que avaliou as características da carcaça de novilhos de diferentes grupos genéticos abatidos aos 14 meses de idade, a correlação verificada foi de -0,19.

Os valores médios referentes às características que expressam musculosidade e maturidade fisiológica da carcaça, de acordo com a categoria e grupo genético, são apresentados na Tabela 3. Analisando a conformação da carcaça, que representa o grau de musculosidade na região anterior e principalmente na região posterior da carcaça, nota-se que os animais 5/8CH 3/8NE apresentaram carcaças com maior expressão muscular (11,00 pontos), classificadas como “boa típica”, que os 5/8NE 3/8CH (10,33 pontos), que tiveram suas carcaças classificadas como "boa menos". Este resultado demonstra o marcante efeito genético aditivo da raça $\mathrm{CH}$ para musculosidade. Em seu estudo, Vaz et al. (2002 a) relataram maior conformação para os novilhos 75\% Charolês (11,3 pontos), em relação aos 75\% Nelore (10,4 pontos), e verificaram correlação positiva com espessura de coxão $(\mathrm{r}=0,46)$ e área do músculo Longissimus dorsi $(\mathrm{r}=0,56)$.

A conformação tem relevante importância comercial, em virtude do melhor aspecto visual apresentado pela carcaça com maior hipertrofia muscular, preferida pelos açougues e consumidores (Müller, 1987). Neste estudo, a conformação da carcaça correlacionou-se positivamente com várias características que expressam musculosidade, como área do músculo Longissimus dorsi $(r=0,35)$, espessura de coxão $(r=0,23)$ e perímetro de braço $(r=0,15)$ (Tabela 6). Resultados 
Tabela 3 - Médias e erros-padrão para conformação, espessura de coxão, perímetro de braço, área do músculo Longissimus dorsi (ALD), ALD/100 kg peso carcaça fria (PCF) e maturidade fisiológica da carcaça, de acordo com a categoria e o grupo genético

Table 3 - Means and standard errors for conformation, cushion thickness, arm perimeter, "Longissimus dorsi" muscle area (LDA), LDA/100 kg cold carcass weight (CCW) and physiologic maturity of carcass, according to category and genetic group

\begin{tabular}{|c|c|c|c|}
\hline \multirow{2}{*}{$\begin{array}{l}\text { Grupo genético } \\
\text { Genetic group }\end{array}$} & \multicolumn{2}{|c|}{$\begin{array}{c}\text { Categoria } \\
\text { Category }\end{array}$} & \multirow[t]{2}{*}{$\begin{array}{l}\text { Média } \\
\text { Mean }\end{array}$} \\
\hline & $\begin{array}{l}\text { Jovem } \\
\text { Steer }\end{array}$ & $\begin{array}{c}\text { Superjovem } \\
\text { Young steer }\end{array}$ & \\
\hline
\end{tabular}

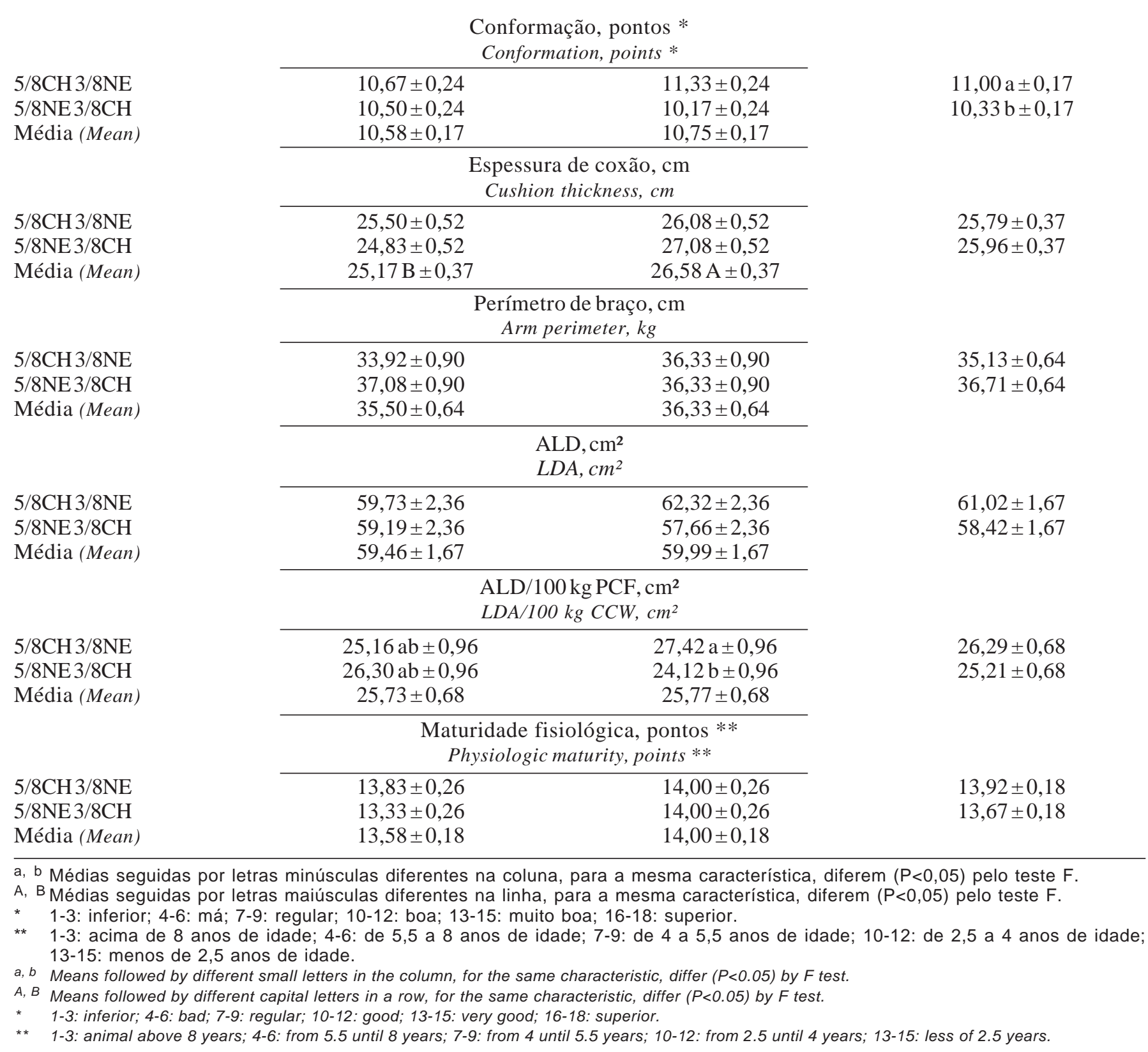

semelhantes foram relatados por Perobelli et al. (1994), Perobelli et al. (1995) e Vaz et al. (2002a).

Entre as categorias, não houve diferença significativa para conformação, com valores médios de 10,75 pontos, para os animais superjovens, e de 10,58 pontos para os jovens. Na literatura, são citadas diferenças acentuadas na conformação entre diferentes categorias. Estudando categorias com diferenças de idade maiores que as deste estudo, Vaz et al. (2002c) verificaram conformação superior para novilhos (10,33 pontos) em relação a vacas de descarte (7,83 pontos). Mesmo comportamento foi reportado 
Tabela 4 - Médias e erros-padrão para comprimentos de carcaça, de perna e de braço, espessura de gordura subcutânea (EGS) e EGS/100 kg peso de carcaça fria (PCF), de acordo com a categoria e o grupo genético Table 4 - Means and standard errors for carcass, leg and arm length, subcutaneous fat thickness (SFT) and SFT/100 kg cold carcass weight (CCW), according to category and genetic group

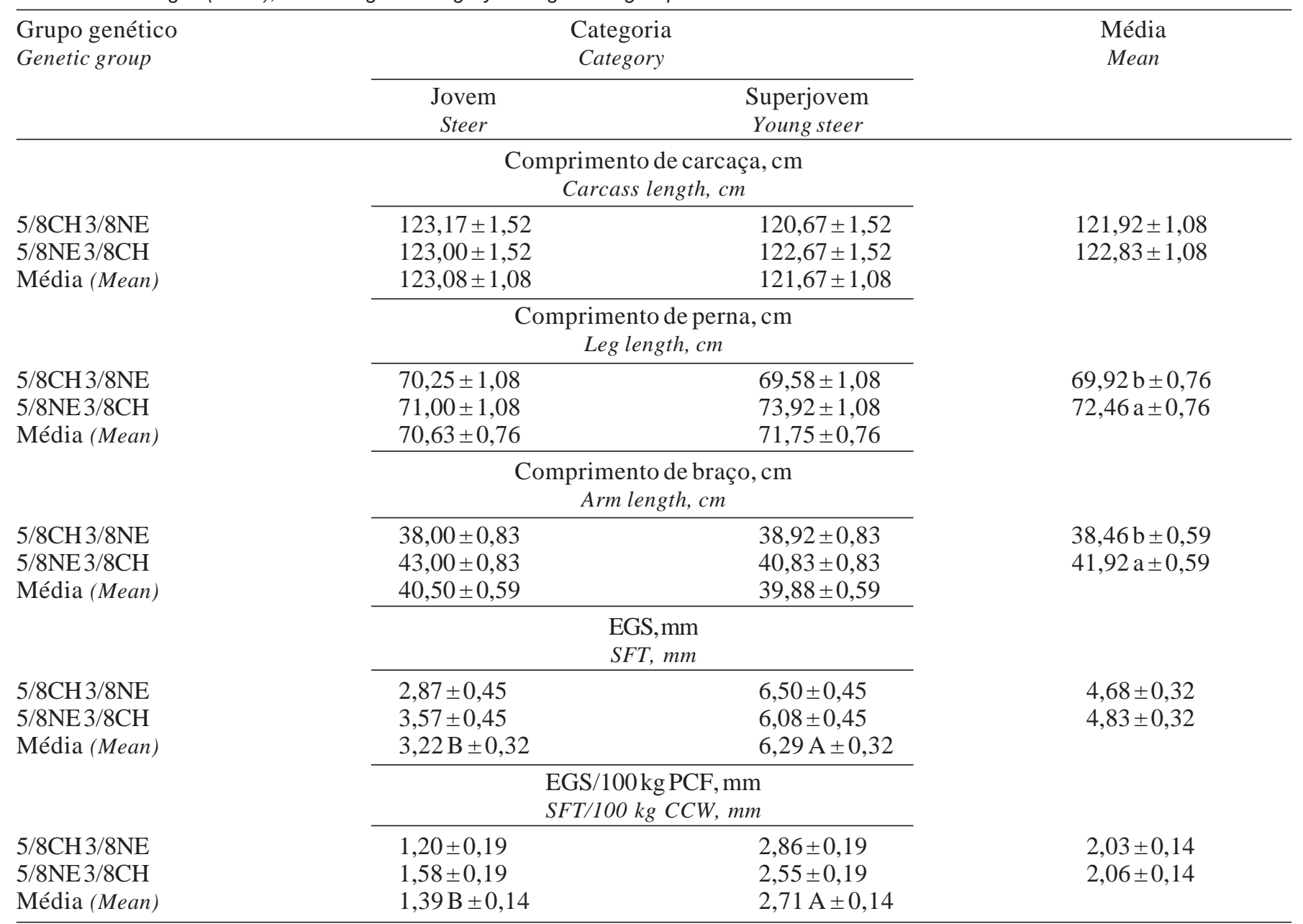

a, b Médias seguidas por letras minúsculas diferentes na coluna, para a mesma característica, diferem $(P<0,05)$ pelo teste $F$ A, B Médias seguidas por letras maiúsculas diferentes na linha, para a mesma característica, diferem $(P<0,05)$ pelo teste $F$.

$a, b$ Means followed by different small letters in the column, for the same characteristic, differ $(P<0.05)$ by $F$ test.

$A, B$ Means followed by different capital letters in a row, for the same characteristic, differ $(P<0.05)$ by $F$ test.

por Towsend et al. (1990a), ao trabalharem com novilhos Charolês de dois ou três anos, e Towsend et al. (1990 b), com novilhos de 2,5 anos ou vacas de descarte Charolês.

Similaridade para conformação em novilhos jovens 5/8NE 3/8CH foi relatada por Arboitte et al. (2004), ao avaliarem diferentes pesos de abate por Peixoto et al. (2003), avaliando diferentes pesos ao início da terminação, e por Costa et al. (2002), ao estudarem novilhos superjovem Aberdeen Angus abatidos com diferentes pesos.

Os animais superjovens apresentaram carcaças com maiores valores de espessura de coxão $(26,58 \mathrm{~cm})$ que os animais jovens $(25,17 \mathrm{~cm})$. Para a área do músculo Longissimus dorsi, não houve diferença significativa entre os efeitos avaliados. Os valores médios oscilaram entre 58,42 e $61,02 \mathrm{~cm}^{2}$. Leve superioridade numérica foi verificada na carcaça dos animais 5/8CH 3/8NE $\left(61,02 \mathrm{~cm}^{2}\right)$ em relação aos 5/8NE 3/8CH $\left(58,42 \mathrm{~cm}^{2}\right)$, havendo interação significativa quando esta característica foi ajustada para $100 \mathrm{~kg}$ de peso de carcaça fria (PCF). Novilhos superjovem 5/8CH 3/8NE apresentaram valores superiores em relação aos 5/8NE 3/8CH de mesma categoria (27,42 vs $24,12 \mathrm{~cm}^{2} / 100 \mathrm{~kg}$ PCF).

Estudando as características da carcaça, Faturi et al. (2002) verificaram melhor conformação (11,08 vs 10,94 pontos) e maior área do músculo Longissimus dorsi (69,08 vs $63,23 \mathrm{~cm}^{2}$ ) para novilhos mestiços filhos de touros Charolês que para os filhos de touros 
Nelore. Avaliando diferentes raças taurinas e zebuínas, Peacock et al. (1979) e DeRouen et al. (1992) concluíram que a raça Charolês foi a que apresentou maior efeito genético para a característica área do músculo Longissimus dorsi. Avaliando a segunda geração de cruzamento alternado entre as raças Charolês e Nelore, Vaz (1999) verificaram maior ALD (70,8 vs $\left.65,9 \mathrm{~cm}^{2}\right)$ e ALD/100 kg PCF (28,7 vs $\left.27,2 \mathrm{~cm}^{2}\right)$ em novilhos 3/4CH 1/4NE em relação aos 3/4NE 1/4CH.

Quanto à maturidade fisiológica, não houve diferença $(\mathrm{P}>0,05)$ entre os diferentes níveis dos fatores estudados, o que demonstra que a diferença de 7,6 meses de idade no momento do abate entre as categorias estudadas (22,8 meses para jovem e 15,2 meses para superjovem) não foi suficiente para promover diferenças no grau de ossificação das cartilagens torácicas, lombares e entre as vértebras sacrais. Contudo, animais da categoria superjovem apresentaram superioridade numérica (14,00 pontos) em relação aos animais jovens (13,58 pontos), assim como os animais 5/8CH 3/8NE (13,92 pontos) em relação aos 5/8NE 3/8CH (13,67 pontos), demonstrando tendência de menor velocidade de maturação fisiológica.

Em estudos envolvendo terminação de novilhos superjovens (Costa et al., 2002) e jovens (Arboitte et al., 2004) abatidos com diferentes pesos e, conseqüentemente, idades diferentes, a maturidade fisiológica foi similar. Towsend et al. (1990a), avaliando as características da carcaça de novilhos de dois ou três anos de idade terminados em confinamento, não constataram diferença significativa para maturidade fisiológica.

Na Tabela 4 encontram-se os resultados referentes às características métricas e à espessura de gordura subcutânea da carcaça, de acordo com o grupo genético e a categoria dos animais.

Analisando as diferentes categorias, nota-se que houve similaridade para as diferentes características estudadas, o que pode ser explicado pela similaridade no peso de abate e pelos pesos de carcaça quente e fria, em decorrência da correlação positiva entre estas variáveis com as características métricas da carcaça (Tabela 6).

Maiores comprimentos de braço e tendência numérica de maiores comprimentos de carcaça e de perna em novilhos jovens 5/8NE 3/8CH terminados em confinamento, que apresentaram ganho de peso médio diário de 2,3 kg/dia (30 dias de confinamento), comparados com os que ganharam $1,5 \mathrm{~kg} / \mathrm{dia}$ (94 dias de confinamento) e foram abatidos com peso similar foram relatados por Peixoto et al. (2003) e Bernardes et al. (2003), que, como no presente estudo, verificaram crescimento compensatório para os novilhos jovens.

Entre os grupos genéticos, os animais 5/8NE 3/8CH apresentaram carcaças com maiores comprimentos de perna ( 72,46 vs $69,92 \mathrm{~cm})$ e de braço $(41,92$ vs 38,46 cm) e tendência de maior perímetro de braço ( $\mathrm{P}=$ 0,0952) (36,71 vs 35,13 cm; Tabela 4) em relação aos animais do grupo genético 5/8CH 3/8NE. Contudo, o comprimento de carcaça foi similar. Avaliando as características da carcaça e da carne de novilhos resultantes do cruzamento alternado entre as raças CH e NE, Vaz (1999) verificou que, na segunda geração de cruzamento, animais 3/4NE 1/4CH apresentaram maiores comprimentos de perna (74 vs 72 $\mathrm{cm}$ ) e de braço $(41,5 \mathrm{vs} 39,7 \mathrm{~cm})$ que animais $3 / 4 \mathrm{CH}$ 1/4NE. O autor relatou ainda que estes resultados seguiram a mesma tendência apresentada pelas raças definidas ( $\mathrm{CH}$ e $\mathrm{NE}$ ), em que animais zebuínos se caracterizam por membros mais compridos, por razões de adaptabilidade (Berg \& Butterfield, 1976).

Em cruzamentos com raças taurinas, diversos estudos comprovaram que a inclusão de sangue Nelore ao genótipo resulta em aumento no comprimento dos membros, como demonstrado por Restle et al. (1999 a) e Vaz et al. (2002b), que trabalharam com as raças Hereford e Nelore, Feijó et al. (1997), com Simental e Nelore, e Restle et al. (2000), com Charolês e Nelore.

Quanto ao grau de acabamento da carcaça, representado pela espessura de gordura subcutânea, verificou-se que animais superjovens apresentaram carcaças com maior deposição de gordura $(6,29$ $\mathrm{mm})$ que os jovens (3,22 $\mathrm{mm})$, com diferença de 95\%. Entre os grupos genéticos, não houve diferença significativa, com valores médios de 4,68 mm para os novilhos 5/8CH 3/8NE e de 4,83 mm, para os 5/8NE 3/8CH. Entre novilhos mestiços filhos de touros $\mathrm{CH}$ ou NE, Faturi et al. (2002) não observaram diferença significativa para espessura de gordura subcutânea, apesar da tendência de superioridade para os mestiços filhos de touros NE (5,17 vs 6,31 mm). Vaz (1999) relatou carcaças com maior acabamento em novilhos 3/4NE 1/4CH (3,4 mm) em relação aos 3/4CH 1/4NE (2,8 mm). Quando a espessura de gordura subcutânea foi ajustada para peso de carcaça fria, os resultados seguiram o mesmo comportamento, conforme discutido anteriormente, ou seja, grau de acabamento superior na carcaça dos animais superjovem e similaridade entre os grupos genéticos. 
Tabela 5 - Médias e erros-padrão para peso absoluto e percentual de traseiro, dianteiro e costilhar da carcaça, de acordo com a categoria e o grupo genético

Table 5 - Means and standard errors for absolute weight and percentage of carcass forequarter, sidecut and sawcut, according to category and genetic group

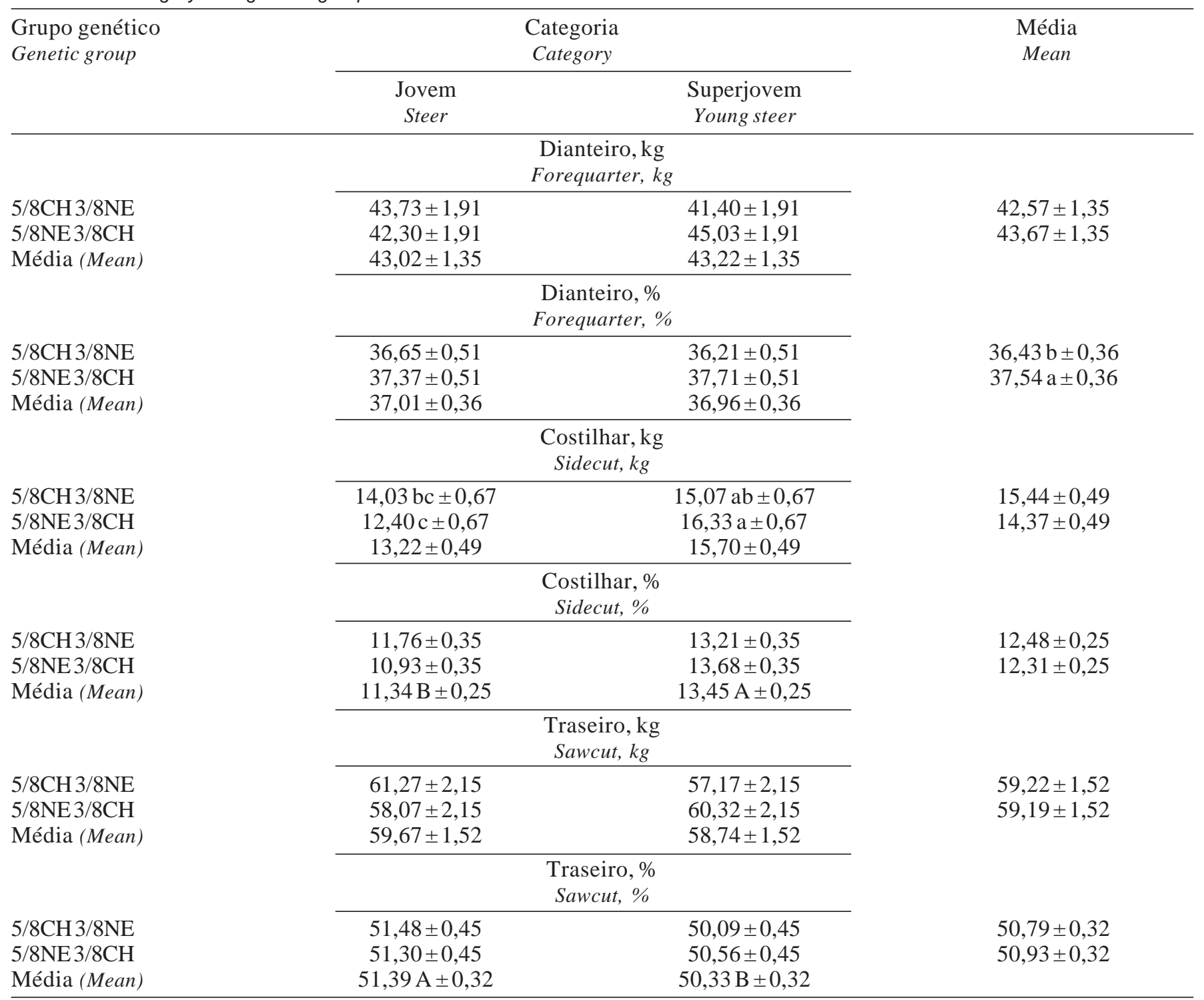

a, b, c Médias seguidas por letras minúsculas diferentes, para a mesma característica, diferem $(P<0,05)$ pelo teste Tukey.

$a, b \quad$ Médias seguidas por letras minúsculas diferentes na coluna, para a mesma característica, diferem $(P<0,05)$ pelo teste $F$.

A, B Médias seguidas por letras maiúsculas diferentes na linha, para a mesma característica, diferem $(P<0,05)$ pelo teste $F$.

$a, b, c$ Means followed by different small letters, for the same characteristic, differ $(P<0.05)$ by Tukey test.

$a, b \quad$ Means followed by different small letters in the column, for the same characteristic, differ $(P<0.05)$ by $F$ test.

$A, B \quad$ Means followed by different capital letters in a row, for the same characteristic, differ $(P<0.05)$ by $F$ test.

Costa et al. (2002) reportaram que a espessura de gordura exigida nas carcaças pelos frigoríficos brasileiros situa-se entre 3 e $6 \mathrm{~mm}$. Abaixo de $3 \mathrm{~mm}$, ocorre o escurecimento da parte externa dos músculos que recobrem a carcaça, reduzindo seu valor comercial. Por outro lado, cobertura de gordura superior a $6 \mathrm{~mm}$ representa recorte com eliminação do excesso de gordura de cobertura antes da pesagem da carcaça, o que acarreta maior custo operacional para o frigorífico e perda de peso da carcaça quando o animal é comercializado a rendimento, incidindo em prejuízo para o produtor.

Neste estudo, o maior acabamento das carcaças dos animais superjovens foi reflexo da alteração da composição do ganho de peso, resultante do maior período de terminação, confirmada pelas correlações positivas entre espessura de gordura subcutânea com percentual de gordura $(r=0,75)$ e quantidade total de gordura na carcaça $(r=0,65)$, sendo estas duas últimas características apresentadas por Pacheco et al. (2005b). 


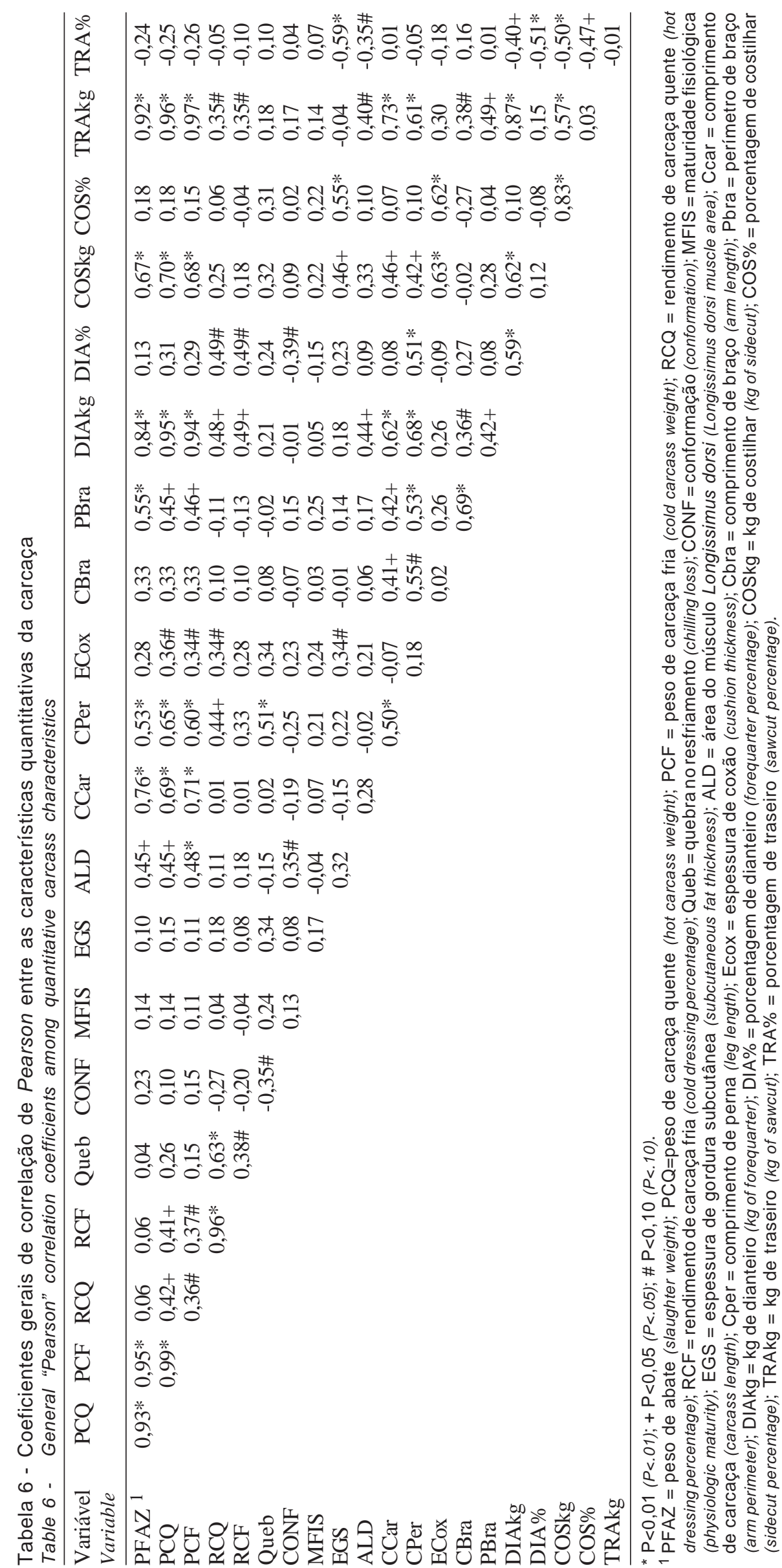


Na Tabela 5 constam as médias referentes aos pesos e percentuais dos cortes comerciais da carcaça dos novilhos, de acordo com a categoria e o grupo genético. Analisando os pesos absolutos dos cortes comerciais, constatou-se que o corte dianteiro e o traseiro, também denominado traseiro especial ou serrote, não apresentaram diferença entre as carcaças dos animais de diferentes categorias e grupos genéticos.

Para o costilhar, também denominado ponta-deagulha, houve interação significativa, sendo maior nos animais 5/8NE 3/8CH superjovens $(16,33 \mathrm{~kg})$ em relação aos 5/8CH 3/8NE (14,03 kg) e 5/8NE 3/8CH jovens $(12,40 \mathrm{~kg})$.

No entanto, quando os cortes foram avaliados por $100 \mathrm{~kg}$ de carcaça fria, animais da categoria superjovem apresentaram carcaças com maior porcentagem de costilhar (13,45 vs 11,34), em razão da maior quantidade de gordura acumulada nesta região da carcaça conforme coeficiente de correlação de 0,55 entre percentual de costilhar e espessura de gordura subcutânea. Berg \& Butterfield (1976) relatam ainda que a deposição de gordura não só de cobertura, mas também a intramuscular, pode alterar a participação dos cortes comerciais na carcaça, o que, neste estudo, foi confirmado pela correlação positiva entre percentual de costilhar e marmoreio $(r=0,34)$, sendo esta última característica apresentada por Pacheco et al. (2005b).

Comparando-se a relação do percentual de costilhar com a avaliação subjetiva do estado corporal ao abate (Pacheco et al., 2005a), que também avalia o grau de acabamento dos animais, houve correlação positiva, embora com menor magnitude ( $r=0,24)$, se comparado com a espessura de gordura subcutânea neste estudo $(r=0,55)$. Isto porque, para avaliação do estado corporal, considera-se o acúmulo de gordura em diferentes partes do corpo do animal (região lombar, peitoral, garupa e inserção da cauda) e também nas costelas.

O percentual de traseiro foi menor nos animais superjovens (50,33\%) que nos jovens (51,39\%), em decorrência das variações nas porcentagens de costilhar, uma vez que a porcentagem de dianteiro foi similar entre as diferentes categorias. Entre os cortes comerciais da carcaça, o traseiro é o mais valorizado, uma vez que contém os músculos de maior valor comercial, gerando maior remuneração para o frigorífico. Avaliando a proporção dos cortes comerciais da carcaça de novilhos abatidos aos dois ou três anos de idade, Towsend et al. (1990 a) verificaram similaridade para percentual de traseiro e de dianteiro e superioridade no percentual de costilhar para os animais com maior idade ao abate.

Quanto ao efeito do grupo genético, verificou-se superioridade dos novilhos com maior predominância de Nelore no genótipo para percentagem de dianteiro nas carcaças. Em seu estudo, Faturi et al. (2002) verificaram similaridade no percentual dos diferentes cortes comerciais da carcaça entre novilhos mestiços filhos de touros Charolês ou de touros Nelore, corroborando os resultados obtidos por Vaz (1999), que analisou a segunda geração de cruzamento alternado entre as raças $\mathrm{CH}$ e $\mathrm{NE}$.

\section{Conclusões}

Independentemente da manipulação da idade de abate e da composição genética dos animais, as carcaças apresentam grau de acabamento adequado.

Carcaças de novilhos jovens são mais desejadas, em razão da maior proporção do corte comercial traseiro, mais valorizado comercialmente.

\section{Literatura Citada}

ANUALPEC - Anuário da Pecuária Brasileira. São Paulo: OESP Gráfica, 2003. 400p.

ARBOITTE, M.Z.; RESTLE, J.; ALVES FILHO, D.C. et al. Características da carcaça de novilhos 5/8 - Nelore 3/8 Charolês abatidos em diferentes estádios de desenvolvimento. Revista Brasileira de Zootecnia, v.33, n.4, p.969-977, 2004.

BERG, R.T.; BUTTERFIELD, R.M. New concepts of cattle growth. Sydney: Sydney University Press, 1976. 240p.

BERNARDES, R.A.C.; ALVES FILHO, D.C.; RESTLE, J. et al. Composição física e cortes comerciais da carcaça de novilhos com diferentes pesos ao início do confinamento, abatidos com $500 \mathrm{~kg}$. In: REUNIÃO ANUAL DA SOCIEDADE BRASILEIRA DE ZOOTECNIA, 40., 2003, Santa Maria. Anais... Santa Maria: SBZ [2003], CD-ROM, cód 6_326.

COSTA, E.C.; RESTLE, J.; VAZ, F.N. et al. Características da carcaça de novilhos Red Angus superprecoces abatidos com diferentes pesos. Revista Brasileira de Zootecnia, v.31, n.1, p.119-128, 2002.

DeROUEN, S.M.; FRANKE, D.E.; BIDNER, T.D. et al. Direct and maternal genetic effects for carcass traits in beef cattle. Journal of Animal Science, v.70, n.12, p.3677-3685, 1992.

FATURI, C.; RESTLE, J.; BRONDANI, I.L. et al. Características da carcaça e da carne de novilhos de diferentes grupos genéticos alimentados em confinamento com diferentes proporções de grão de aveia e grão de sorgo no concentrado. Revista Brasileira de Zootecnia, v.31, n.5, p.2024-2035, 2002.

FEIJÓ, G.L.D.; EUCLIDES FILHO, K.; FIGUEIREDO, G.R. et al. Avaliação de carcaças de Nelore e F1's europeu-Nelore a um grau de acabamento constante. In: REUNIÃO ANUAL DA SOCIEDADE BRASILEIRA DE ZOOTECNIA, 34. 1997, Juiz de Fora. Anais... Juiz de Fora: Sociedade Brasleira de Zootecnia, 1997. p.133-135. 
FLORES, J.L.C. Desempenho em confinamento e características de carcaça e da carne de bovinos de diferentes grupos genéticos abatidos aos quatorze meses. Santa Maria: Universidade Federal de Santa Maria, 1997. 109p. Dissertação (Mestrado em Zootecnia) - Universidade Federal de Santa Maria, 1997.

GALVÃO, J.G.; FONTES, C.A.A.; PIRES, C.C. et al. Características e composição da carcaça de bovinos não-castrados, abatidos em três estágios de maturidade (estudo II) de três grupos raciais. Revista da Sociedade Brasileira de Zootecnia, v.20, p.502-512, 1991.

LAWRIE, R.A. Ciência de la carne. Zaragoza: Acribia, 1970. 342p.

MORENO, J.A. Clima do Rio Grande do Sul. Porto Alegre: Secretaria da Agricultura, 1961. 41p.

MÜLLER, L. Normas para avaliação de carcaças e concurso de carcaças de novilhos. 2.ed. Santa Maria: Universidade Federal de Santa Maria, 1987. 31p.

NATIONAL RESEARCH COUNCIL - NRC. Nutrient requirements of domestic animals. 7.ed. Washington, D.C.: National Academy Press, 1996. 242p.

PACHECO, P.S.; RESTLE, J.; SILVA, J.H.S. et al. Desempenho de novilhos jovens e superjovens de diferentes grupos genéticos terminados em confinamento. Revista Brasileira de Zootecnia, v.34, n.3, p.963-975, 2005a.

PACHECO, P.S.; RESTLE, J.; SILVA, J.H.S. et al. Composição física da carcaça e qualidade da carne de novilhos jovens e superjovens de diferentes grupos genéticos. Revista Brasileira de Zootecnia, v.34, n.5, p.1691-1703, 2005b.

PEACOCK, F.M.; PALMER, A.Z.; CARPENTER, J.W. et al. Breed and heterosis effects on carcass characteristics of Angus, Brahman, Charolais and crossbred steers. Journal of Animal Science, v.49, n.2, p.391, 1979.

PEIXOTO, L.A.O.; RESTLE, J.; ALVES FILHO, D.C. et al. Características quantitativas da carcaça de novilhos com diferentes pesos ao início do confinamento, abatidos aos 500 kg. In: REUNIÃO ANUAL DA SOCIEDADE BRASILEIRA DE ZOOTECNIA, 40., 2003, Santa Maria. Anais... Santa Maria: SBZ [2003], CD-ROM, cód 6_325.

PEROBELLI, Z.V.; MÜLLER, L.; RESTLE, J. Estudo da qualidade das carcaças e da carne de vacas de descarte de dois grupos genéticos. Ciência Rural, v.24, n.3, p.613-616, 1994.

PEROBELLI, Z.V.; RESTLE, J.; MÜLLER, L. Estudo das carcaças de vacas de descarte das raças Charolês e Nelore. Pesquisa Agropecuária Brasileira, v.30, n.3, p.409-412, 1995.

RESTLE, J.; BRONDANI, I.L.; BERNARDES, R.A.C. O novilho superprecoce. In: RESTLE, J. (Ed.) Confinamento, pastagens e suplementação para produção de bovinos de corte. Santa Maria: Universidade Federal de Santa Maria, 1999. p.191-214.

RESTLE, J.; KEPLIN, L.A.S.; VAZ, F.N. Características quantitativas da carcaça de novilhos Charolês, abatidos com diferentes pesos. Pesquisa Agropecuária Brasileira, v.32, n.8, p.851-856, 1997.
RESTLE, J.; VAZ, F.N. Eficiência e qualidade na produção de carne bovina. In: REUNIÃO ANUAL DA SOCIEDADE BRASILEIRA DE ZOOTECNIA, 40., 2003, Santa Maria. Anais... Santa Maria: SBZ [2003], 34p., CD-ROM, cód. Palestra11.

RESTLE, J.; VAZ, F.N.; FEIJÓ, G.L.D. et al. Características de carcaça de bovinos de corte inteiros ou castrados de diferentes composições raciais Charolês x Nelore. Revista Brasileira de Zootecnia, v.29, n.5, p.1371-1379, 2000.

RESTLE, J.; VAZ, F.N.; QUADROS, A.R.B. Características de carcaça e da carne de novilhos de diferentes genótipos de Hereford x Nelore. Revista Brasileira de Zootecnia, v.28, n.6, p.1245-1251, 1999a.

STATISTICAL ANALYSIS SYSTEMS - SAS. User's guide. Version 6, Cary: 1997. v.2, 1052p.

TOWSEND, M.; RESTLE, J.; MÜLLER, L. Avaliação qualitativa de carcaças de novilhos com diferentes idades confinados por dois invernos subseqüentes. In: REUNIÃO ANUAL DA SOCIEDADE BRASILEIRA DE ZOOTECNIA, 27., 1990, Campinas. Anais... Campinas: Sociedade Brasileira de Zootecnia, 1990a. p.359.

TOWSEND, M.; RESTLE, J.; PASCOAL, L.L. et al. Características qualitativas das carcaças de novilhos e vacas terminadas em confinamento. In: REUNIÃO ANUAL DA SOCIEDADE BRASILEIRA DE ZOOTECNIA, 27., 1990, Campinas. Anais... Campinas: Sociedade Brasileira de Zootecnia, 1990b. p.361.

VAZ, F.N. Cruzamento alternado das raças Charolês e Nelore: características de carcaça e da carne de novilhos abatidos aos dois anos. Santa Maria: Universidade Federal de Santa Maria, 1999. 58p. Dissertação (Mestrado em Zootecnia) - Universidade Federal de Santa Maria, 1999.

VAZ, F.N.; RESTLE, J.; ALVES FILHO, D.C. et al. Características de carcaça e da carne de novilhos filhos de vacas $1 / 2$ Nelore 1/2 Charolês e 1/2 Charolês 1/2 Nelore acasaladas com touros Charolês ou Nelore. Revista Brasileira de Zootecnia, v.31, n.4, p.1734-1743, 2002a.

VAZ, F.N.; RESTLE, J.; PACHECO, P.S. et al. Características de carcaça e da carne de novilhos superprecoce de três grupos genéticos, gerados por fêmeas de dois anos. Revista Brasileira de Zootecnia, v.31, n.5, p.1973-1982, 2002b.

VAZ, F.N.; RESTLE, J.; QUADROS, A.R.B. et al. Características da carcaça e da carne de novilhos e de vacas de descarte Hereford, terminados em confinamento. Revista Brasileira de Zootecnia, v.31, n.3, p.1501-1510, 2002c (Suplemento). 